\title{
Design and Development of Atenolol Matrix Tablet Employing Natural and Synthetic Polymers
}

\author{
Adity Bhowmik*, Rajia Sultana Nijhu, Tajnin Ahmed, Sharmin Sultana \\ Department of Pharmacy, Stamford University Bangladesh, 51-Siddeswari Road, Dhaka- 1217, Bangladesh.
}

\begin{tabular}{l}
\hline ARTICLE INFO \\
\hline Article history: \\
Received on: $23 / 05 / 2013$ \\
Revised on: $05 / 07 / 2013$ \\
Accepted on: $01 / 09 / 2013$ \\
Available online: $30 / 09 / 2013$ \\
\hline
\end{tabular}

Key words:

Atenolol matrix tablet,

Xanthan Gum, Gum

Accacia,Tragacanth ,Hupu

Gum .

\begin{abstract}
The main objective of the present work was to develop sustained release matrix tablets of Atenolol. To reduce the frequency of administration and to improve the patient compliance, a once daily sustained release formulation of Atenolol is desirable. So sustained release Matrix Tablet of Atenolol was designed by using different polymers viz.Starch, Xanthan Gum, Vee Gum, Guar Gum, Gum Accacia, Tragacanth, Hupu Gum were used as natural polymers and Eudragit-L100, Ethyl Cellulose, Sodium Carboxy Methyl Cellulose (Na-CMC) ,Hydroxy Propyl Methyl Cellulose (HPMC) (5\&15cps), Methyl Cellulose, Kollidon were used as synthetic polymers. After fixing the ratio of drug and polymer for control the release of drug up to desired time, the release rates were modulated by Single polymer, combination of two different rates controlling material. The FT-IR study revealed that there was no chemical interaction between drug and excipients. The granules were prepared by dry granulation method. Precompressional parameters i.e. angle of repose, percent compressibility, and Hausner's ratios were studied. These results indicate that granules are good flowing characteristics. After evaluation of physical properties like Weight variation, Hardness, Thickness, Friability of tablet, the different formulations checked for the Percentage Drug content which having good uniformity. The results of drug dissolution studies showed improved drug release, retardation effects of the polymers and could achieve better performance. After eight hours dissolution test, dissolution profiles showed that better sustained release was observed from starch and veegum containing formulation and eudragit and ethyl cellulose containing formulation of atenolol matrix tablet. It was also observed that the presence of starch caused an increase in the release rate of atenolol matrix tablet. The present study shows a relatively simple method to design and develop Atenolol matrix tablet.
\end{abstract}

\section{INTRODUCTION}

Atenolol is a selective $\beta_{1}$ receptor antagonist, a drug belonging to the group of beta blockers (sometimes written $\beta$ blockers), a class of drugs used primarily in cardiovascular diseases. Introduced in 1976, atenolol was developed as a replacement for propranolol in the treatment of hypertension. The chemical works by slowing down the heart and reducing its workload. Unlike propranolol, atenolol does not pass through the blood-brain barrier thus avoiding various central nervous system side effects. In atenolol matrix tablet based on different polymers release ratio study, an attempt was made to design and formulate atenolol matrix tablet and also focus to the release ratio of different natural and synthetic polymers for designing a sustain release drug(Agon et al., 1991) Sustained release dosage forms are designed to release a drug at a predetermined rate in order to

* Corresponding Author

Adity Bhowmik, Email: adity_bhowmik@yahoo.com maintain a constant drug concentration for a specific period of time with minimum side effects. Matrix formation starts with application of force which brings polymer particles into close contact. Release rate of a sustain release drug depends on the nature of polymers (Altaf et al., 2003; Strubel et al., 2000; Basak et al., 2006; and Bechgaar et al., 1980) There are two types of polymers such as natural and synthetic polymers. Naturally occurring polymers offer several advantages relative to synthetic polymers, since the surrounding biological environment can recognize and metabolically process the substance through established pathways (Strubel et al., 2000) Synthetic polymers can create toxicity, chronic inflammation, and clearance issues that are of less importance with natural polymers. However, natural polymers have historically been plagued with several drawbacks, including immunogenicity, lot-to-lot variability, and structural complexity, and inadequate biomechanical properties (Bechgaar et al., 1980) Recent developments to reduce these unfa vorable properties 
have led to a substantial number of successful biopolymers and biopolymers applications based on the unique properties of naturally occurring polymers and their chemically-modified derivatives. The matrix tablet by direct compression has attracted much attention due to its technological simplicity in comparison to other controlled release systems. It requires fewer unit operations, less machinery, reduced number of personnel and processing time, increased product stability and production rate (Rahman et al., 2011).

\section{MATERIALS AND METHODS}

\section{Chemicals}

Atenolol (Midford Hospital, Bangladesh). Edragit L100 (Dow Chemical co, USA),Ethyl cellulose (Dow Chemical co, USA),Sodium carboxy methyl cellulose (Dow Chemical co, USA), Hydroxypropyl methylcellulose (Dow Chemical co, USA). Kollidon SR (Techno Pharma,Bangladesh). Xanthan gum (Koster Keune, USA ), Vee gum(Koster Keune, USA ), Guar gum (Koster Keune, USA ), Tragacanth (Koster Keune, USA ). Hydrochloric acid $(37 \%)$ (Merck, Germany) and sodium hydroxide (Merck, Germany).

\section{Instruments}

KBR Press Compression Machine (India), , HACH Spectrophotometer (DR/4000 u), Digital pH meter (LIDA Instrument, model: PHS-25), Manual Hardness Tester (Monsanto type, model-MHT 20, India), Vernier Callipers(model-Triclr brand), Pharmatest Dissolution Test Machine(model-DT70), Electronic Balance (model-M310), Tapped density tester(modelTD 200), Single drum friability tester(model-Pharma test modelF10E/ER), $0.45 \mu$ Disk Filter.

\section{Preparation of matrix tablet}

Drug, polymers and other excipients were weighed separately for 100 tablets for each formulation. The tablets were prepared by direct compression method. Active ingredient (Atenolol) and polymers [Eudragit L100, Ethyl Cellulose, NaCMC, HPMC as synthetic and Starch, Xanthan Gum, Veegum and Guargum as natural polymer] were passed through \#18 sieve and placed in a poly bag. Then these ingredients were blended in a poly bag for 20 minutes.

After then Lactose MH and Avicel PH102 and sodium starch glycolate were weighed separately and sieved through mesh \# 18 and placed in a poly bag for another 10 minutes blending. After blending, Aerosil-200 (0.5\%) and Magnesium Stearate $(0.5 \%)$ were passed through \#40 sieve and placed in the same poly bag and were blended for 3 minutes. Blended granules were discharged into the double polythene bags and closed properly. Blended granules were then compressed using KBR Compress machine equipped with $10.0 \mathrm{~mm}$ round biconvex punch and die set. After compression, the prepared tablets were stored in an air tight container for further evaluation.

Table. 1: The active ingredient, polymers and excipients used in the proposed formulations of atenolol matrices Containing Synthetic polymers (Eudragit L100 based) and their composition (mg).

\begin{tabular}{|c|c|c|c|c|c|c|c|c|c|}
\hline Code & Atenolol & EudragitL100 & Ethyl Cellulose & Na-CMC & HPMC & Avicel PH102 & Na-starch-glycolate & Mg-stearate & Aerosil-200 \\
\hline UL-1 & 25 & 52 & - & - & - & 179.1 & 1.3 & 1.3 & 1.3 \\
\hline UL - 2 & 25 & 26 & 26 & - & - & 179.1 & 1.3 & 1.3 & 1.3 \\
\hline UL -3 & 25 & 39 & - & 26 & - & 166.1 & 1.3 & 1.3 & 1.3 \\
\hline UL - 4 & 25 & 52 & - & - & 26 & 154.4 & 1.3 & 1.3 & 1.3 \\
\hline
\end{tabular}

Table. 2 : The active ingredient, polymers and excipients used in the proposed formulations of atenolol matrices Containing natural polymer (Starch based )and their composition $(\mathrm{mg})$

\begin{tabular}{|c|c|c|c|c|c|c|c|c|c|}
\hline Code & Atenolol & Starch & Xnthan gum & Vee gum & Guar gum & Avicel PH102 & Na-starch-glycolate & Mg-stearate & Aerosil-200 \\
\hline S-1 & 25 & 52 & - & - & - & 179.1 & 1.3 & 1.3 & 1.3 \\
\hline$S-2$ & 25 & 26 & 26 & - & - & 179.1 & 1.3 & 1.3 & 1.3 \\
\hline$S-3$ & 25 & 39 & - & 26 & - & 166.1 & 1.3 & 1.3 & 1.3 \\
\hline$S-4$ & 25 & 52 & - & - & 26 & 154.4 & 1.3 & 1.3 & 1.3 \\
\hline
\end{tabular}

Table. 3 : The active ingredient, polymers and excipients used in the proposed formulations of atenolol matrices Containing Synthetic polymers (HPMC 5 $\& 15 \mathrm{cps})$ and their composition (mg).

\begin{tabular}{lcccccccccc}
\hline Code & Atenolol & $\begin{array}{c}\text { HPMC } \\
\text { 5cps }\end{array}$ & $\begin{array}{c}\text { HPMC } \\
\text { 15cps }\end{array}$ & $\begin{array}{c}\text { Methyl } \\
\text { Cellulose }\end{array}$ & Kollidon SR & $\begin{array}{c}\text { Avicel } \\
\text { PH102 }\end{array}$ & $\begin{array}{c}\text { Lactose } \\
\text { MH }\end{array}$ & $\begin{array}{c}\text { Na-starch- } \\
\text { glycolate }\end{array}$ & Mg-stearate & Aerosil-200 \\
\hline H-1 & 25 & 52 & - & - & - & 107.5 & 71.61 & 1.3 & 1.3 \\
H -2 & 25 & - & 52 & - & - & 107.5 & 71.61 & 1.3 & 1.3 \\
H -3 & 25 & 26 & - & 26 & - & 107.5 & 71.61 & 1.3 & 1.3 \\
H -4 & 25 & 26 & - & - & 26 & 107.5 & 71.61 & 1.3 & 1.3 \\
H -5 & 25 & 39 & - & - & - & 120.5 & 71.61 & 1.3 & 1.3 \\
H -6 & 25 & 39 & - & - & - & 192.1 & - & 1.3 & 1.3 & 1.3 \\
H -7 & 25 & 39 & - & - & - & 166.1 & 26 & 1.3 & 1.3 \\
H -8 & 25 & - & 39 & - & - & 166.1 & 26 & 1.3 & 1.3 \\
H -9 & 25 & 19.5 & - & 19.5 & - & 166.1 & 26 & 1.3 & 1.3 \\
H-10 & 25 & 19.5 & - & - & 19.5 & 166.1 & 26 & 1.3 & 1.3 \\
\hline
\end{tabular}


Table. 4: The active ingredient, polymers and excipients used in the proposed formulations of atenolol matrices Containing natural polymer (Gum accacia based) and their composition (mg).

\begin{tabular}{ccccccccccc}
\hline Code & Atenolol & $\begin{array}{c}\text { Gum } \\
\text { accacia }\end{array}$ & Starch & $\begin{array}{c}\text { Traga- } \\
\text { canth }\end{array}$ & $\begin{array}{c}\text { Hupu } \\
\text { gum }\end{array}$ & $\begin{array}{c}\text { Avicel } \\
\text { PH102 }\end{array}$ & Lactose MH & $\begin{array}{c}\text { Na-starch- } \\
\text { glycolate }\end{array}$ & Mg-stearate & Aerosil-200 \\
\hline GA-1 & 25 & 52 & - & - & - & 107.5 & 71.61 & 1.3 & 1.3 \\
GA -2 & 25 & 26 & 26 & - & - & 107.5 & 71.61 & 1.3 & 1.3 \\
GA -3 & 25 & 26 & - & 26 & - & 107.5 & 71.61 & 1.3 & 1.3 \\
GA -4 & 25 & 26 & - & - & 26 & 107.5 & 71.61 & 1.3 & 1.3 \\
GA -5 & 25 & 19.5 & - & 19.5 & - & 166.1 & 26 & 1.3 & 1.3 \\
\hline
\end{tabular}

\section{Evaluation of physical properties of formulation granules}

Loose bulk density and tapped bulk density were calculated according to Shah et al., 1997. The compressibility index of the granules was determined by Carr's compressibility index (Aulton, 1988). The diameter of the powder cone was measured and angle of repose was calculated according to Cooper and Gunn, 1986. Flow property was predicted from Hausner ratio and angle of repose measurement.

\section{Evaluation of physical properties of matrix tablets}

20 Tablets from each formulation were evaluated for the determination of their hardness, thickness, friability and weight variation. Manual harness tester was used to measure the hardness of the tablets while tablet thickness was determined by using vernier caliper. Pharmatest Friability Tester was used to determine the friability of the tablets.

\section{Preparation of dissolution media}

Preparation of $0.1 \mathrm{~N} \mathrm{HCl}: 8.292$ gm of $37 \% \mathrm{HCl}$ (conc) was taken in a $1000 \mathrm{ml}$ volumetric flask and the volume was made up to $1000 \mathrm{ml}$ by adding distilled water. Preparation of phosphate buffer $\mathrm{pH}$ 7.4: $6.8045 \mathrm{gm}$ of potassium dihydrogen phosphate was taken in a $1000 \mathrm{ml}$ volumetric flask and the volume was made up to $1000 \mathrm{ml}$ by adding distilled water and the $\mathrm{pH}$ was adjusted with phosphoric acid to $\mathrm{pH}$ 7.4.

\section{In vitro dissolution study of the tablet matrix}

Drug release studies were conducted using USP-22 dissolution apparatus-2, paddle type (PT-DT70, PHARMA TEST, Germany) at a rotational speed of $50 \mathrm{rpm}$ at $37 \pm 0.5{ }^{\circ} \mathrm{C}$. The dissolution media used were $900 \mathrm{~mL}$ of $\mathrm{P}^{\mathrm{H}} \quad 1.5$ media $(0.1 \mathrm{~N} \mathrm{HCl})$ and $\mathrm{P}^{\mathrm{H}} 7.4$ media $(0.05 \mathrm{M}$ potassium dihydrogen phosphate) were used as dissolution media for first two hours and next six hours respectively according to USP. Sink condition was maintained for the whole experient. Samples $(10 \mathrm{~mL})$ were withdrawn at regular intervals and the same volume of prewarmed $\left(37 \pm 0.5^{\circ} \mathrm{C}\right)$ fresh dissolution medium was replaced to maintain the volume constant. the drug content in each sample was analyzed after suitable dilution with a UV spectrophotometer (DR/400U, USA) at $275 \mathrm{~nm}$. Absorbance of different concentrations was taken at the wavelength $(\lambda \max )$ of $275 \mathrm{~nm}$ of both medium. Then concentration vs. absorbance was plotted and standard curve was prepared.

\section{Scanning electron microscopy (SEM)}

A scanning electron microscope (SEM) is a type of electron microscope that produces images of a sample by scanning over it with a high energy focused beam of electrons. Due to the very narrow electron beam, SEM micrographs have a large depth of field yielding a characteristic three-dimensional appearance useful for understanding the surface structure of a sample (Suzuki et al., 2002).

\section{FT-IR Test}

Fourier Transform Infrared Spectroscopy (FTIR) FTIR tests are commonly used for identification, qualification, comparison and reproducibility of materials in research, quality control and production applications. FTIR techniques include fingerprinting, and the qualitative and quantitative analysis of unknown mixtures.

Fourier Transform Infrared Spectrometers (FTIR) measure the absorption of a progression of infrared light wavelengths by a material. With this qualitative analysis, one can qualify the presence or absence of a raw material in a mixture or a monomer in a pre-polymer.

The FTIR of the mixture is scanned and its spectrum is overlaid with the spectra of candidate ingredients. Common ingredients have common absorbance positions and correlations can offer indications of ingredient commonality (Suzuki et al., 2002).

\section{RESULTS}

\section{Post-compression study of Atenolol SR tablets}

Pre-compression study i.e., powder blend property of both synthetic and natural polymer (Angle of repose, Tapped bulk density, loose bulk density, compressibility index and Hausner's ratio) were found to be satisfactory. All these properties compiled with the official limit as shown in Table 5-Table 8. The physical attributes (weight variation, thickness, hardness, and friability) of the prepared tablets from synthetic and natural polymer were found to be satisfactory.

Typical tablet defects such as capping, chipping and picking were not observed. All these properties compiled with the official limit as shown in Table 9 - Table 12. Drug content of both synthetic and natural polymer was found to be satisfactory. 
Table. 5: Precompression study of the granules Containing Natural Polymers (Starch based).

\begin{tabular}{ccccccc}
\hline Code & $\begin{array}{c}\text { Angle of repose } \\
(\boldsymbol{\theta})\end{array}$ & Tapped bulk & density & Loose bulk density & $\begin{array}{c}\text { Compressibility } \\
\text { Index (\%) }\end{array}$ & Hausner's ratio \\
\hline S-1 & 25.234 & 26 & 29 & 11.538 & 0.897 \\
S -2 & 27.543 & 18 & 22 & 22.222 & 12.000 \\
S -3 & 29.987 & 25 & 28 & 20.818 \\
S -4 & 28.179 & 24 & 29 & 0.892 \\
\hline
\end{tabular}

Table. 6: Precompression study of the granules Containing Synthetic polymers(Eudragit L100 based).

\begin{tabular}{ccccccc}
\hline Formulation & $\begin{array}{c}\text { Angle of repose } \\
(\boldsymbol{\theta})\end{array}$ & Tapped bulk & density & Loose bulk density & $\begin{array}{c}\text { Compressibility } \\
\text { Index (\%) }\end{array}$ & Hausner's ratio \\
\hline E-1 & 29.517 & 24 & 28 & 16.667 & 15.000 \\
E -2 & 22.374 & 20 & 23 & 13.636 \\
E -3 & 26.454 & 22 & 25 & 0.857 \\
E -4 & 28.948 & 20.5 & 24 & 17.073 & 0.869 \\
\hline
\end{tabular}

Table. 7: Precompression study of the granules Containing Synthetic polymers (HPMC 5 \& 15cps).

\begin{tabular}{ccrcccc}
\hline Formula No. & $\begin{array}{c}\text { Angle of repose } \\
(\boldsymbol{\theta})\end{array}$ & Tapped bulk & density & Loose bulk density & $\begin{array}{c}\text { Compressibility } \\
\text { Index (\%) }\end{array}$ & Hausner's ratio \\
\hline H-1 & 26.517 & 21 & 27 & 28.571 \\
H-2 & 22.345 & 22 & 27 & 22.727 & 0.778 \\
H-3 & 26.245 & 22 & 25 & 13.636 \\
H-4 & 24.966 & 22 & 25 & 13.636 & 0.815 \\
\end{tabular}

Table. 8: Precompression study of the granules Containing Natural Polymers (Gum accacia based).

\begin{tabular}{|c|c|c|c|c|c|c|}
\hline Code & $\begin{array}{c}\text { Angle of repose } \\
(\theta)\end{array}$ & Tapped bulk & density & Loose bulk density & $\begin{array}{c}\text { Compressibility } \\
\text { Index (\%) }\end{array}$ & Hausner's ratio \\
\hline GA-1 & 25.234 & 22 & & 25 & 13.636 & 0.880 \\
\hline GA -2 & 27.543 & 18 & & 22 & 22.222 & 0.818 \\
\hline GA -3 & 29.987 & 18 & & 22 & 22.222 & 0.818 \\
\hline GA -4 & 28.179 & 24 & & 29 & 20.833 & 0.828 \\
\hline
\end{tabular}

Table. 9 : Properties of Atenolol SR tablets Containing natural polymers (Starch based).

\begin{tabular}{cccccc}
\hline Code & $\begin{array}{c}\text { Hardness } \\
\left(\mathbf{K g} / \mathbf{c m}^{2}\right)\end{array}$ & $\begin{array}{c}\text { Thickness } \\
(\mathbf{m m})\end{array}$ & $\begin{array}{c}\text { Friability } \\
(\boldsymbol{\%})\end{array}$ & $\begin{array}{c}\text { Drug content } \\
(\boldsymbol{\%})\end{array}$ & $\begin{array}{c}\text { Weight } \\
\text { Variation }(\boldsymbol{\%})\end{array}$ \\
\hline S-1 & 5 & 0.7 & 0.23 & 93 & 0.29 \\
S - & 7 & 0.7 & 0.23 & 96 & 0.33 \\
S -3 & 5 & 0.7 & 0.21 & 94 & 0.29 \\
S -4 & 5 & 0.7 & 0.28 & 93 & 0.33 \\
\hline
\end{tabular}

Table. 10 : Properties of Atenolol SR tablets Containing Synthetic polymers (Eudragit L100 based).

\begin{tabular}{cccccc}
\hline Code & $\begin{array}{c}\text { Hardness } \\
\left(\mathrm{Kg} / \mathbf{c m}^{2}\right)\end{array}$ & $\begin{array}{c}\text { Thickness } \\
(\mathbf{m m})\end{array}$ & $\begin{array}{c}\text { Friability } \\
(\%)\end{array}$ & $\begin{array}{c}\text { Weight } \\
\text { Drug content(\%) }\end{array}$ \\
\hline E-1 & $\mathbf{3 . 5}$ & $\mathbf{0 . 7}$ & $\mathbf{0 . 2 2}$ & $\mathbf{9 2}$ & $\mathbf{9 4}$ \\
E -2 & $\mathbf{3 . 7}$ & $\mathbf{0 . 7}$ & $\mathbf{0 . 2 5}$ & $\mathbf{0 . 2 5}$ \\
E -3 & $\mathbf{3 . 8}$ & $\mathbf{0 . 7}$ & $\mathbf{0 . 2 4}$ & $\mathbf{9 5}$ & $\mathbf{0 . 3 3}$ \\
$\mathrm{E}-4$ & $\mathbf{3 . 9}$ & $\mathbf{0 . 7}$ & $\mathbf{0 . 2 7}$ & $\mathbf{9 6}$ & $\mathbf{0 . 2 3}$ \\
\hline
\end{tabular}

Table. 11 : Properties of Atenolol SR tablets Containing natural polymers (Gum accacia based).

\begin{tabular}{cccccc}
\hline Code & $\begin{array}{c}\text { Hardness } \\
\left(\mathbf{K g} / \mathbf{c m}^{2}\right)\end{array}$ & $\begin{array}{c}\text { Thickness } \\
(\mathbf{m m})\end{array}$ & $\begin{array}{c}\text { Friability } \\
(\boldsymbol{\%})\end{array}$ & $\begin{array}{c}\text { Drug content } \\
(\boldsymbol{\%})\end{array}$ & $\begin{array}{c}\text { Weight } \\
\text { Variation }(\boldsymbol{\%})\end{array}$ \\
\hline GA-1 & 5.7 & 2.49 & 0.55 & 92 & 0.29 \\
GA -2 & 6.0 & 2.37 & 0.42 & 96 & 0.51 \\
GA -3 & 5.9 & 2.41 & 0.29 & 93 & 0.54 \\
GA -4 & 6.4 & 2.46 & 0.51 & 95 & 0.48 \\
\hline
\end{tabular}

Table. 12 : Properties of Atenolol SR tablets Containing Synthetic polymers (HPMC 5\&15cps).

\begin{tabular}{|c|c|c|c|c|c|}
\hline Formula No. & $\begin{array}{l}\text { Hardness } \\
\left(\mathrm{Kg} / \mathrm{cm}^{2}\right)\end{array}$ & $\begin{array}{c}\text { Thickness } \\
(\mathbf{m m})\end{array}$ & $\begin{array}{c}\text { Friability } \\
(\%)\end{array}$ & $\begin{array}{c}\text { Drug content } \\
(\%)\end{array}$ & $\begin{array}{c}\text { Weight } \\
\text { Variation }(\%) \\
\end{array}$ \\
\hline $\mathrm{H}-1$ & 6.0 & 2.46 & 0.61 & 95 & 0.54 \\
\hline H - 2 & 6.3 & 2.44 & 0.73 & 96 & 0.63 \\
\hline H -3 & 6.5 & 2.38 & 0.58 & 92 & 0.59 \\
\hline $\mathrm{H}-4$ & 6.8 & 2.40 & 0.65 & 94 & 0.48 \\
\hline
\end{tabular}




\section{DISSOLUTION PROFILE OF ATENOLOL SR}

Release pattern of sustain release dosage form is controlled by using polymers. From above results, it can be said that after eight hours dissolution test, Starch and vee gum containing formula [S-3] was better sustained release of atenolol SR containing natural polymers and eudragit and ethyl cellulose containing formula [E-2] was better sustained release of atenolol SR containing synthetic polymers.
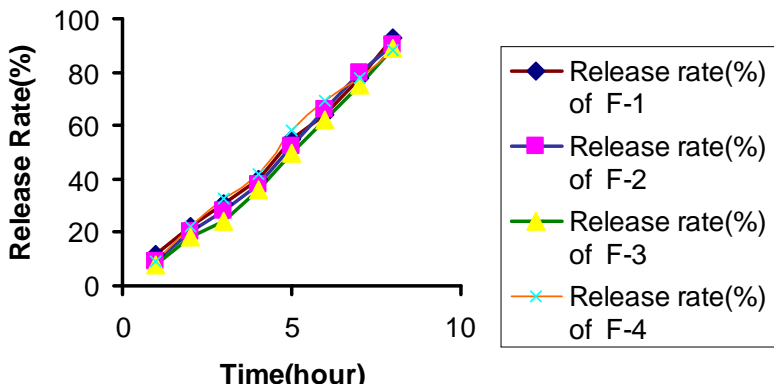

Time(hour)

Fig. 1: Comparative Release Rate of different formulations containing natural polymers(Starch based).

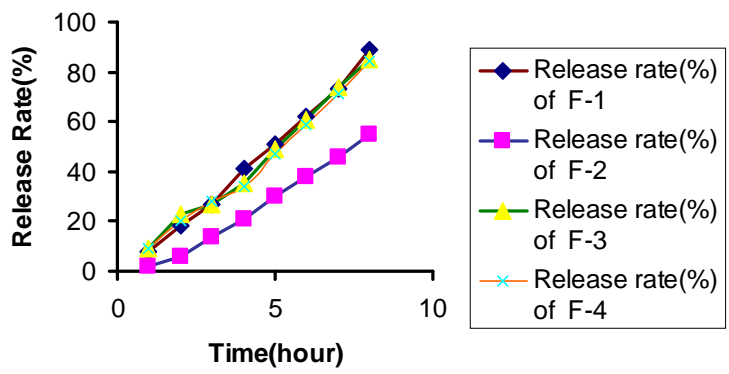

Fig. 2: Comparative Release Rate of different formulations containing synthetic polymers (Eudragit L100 based).

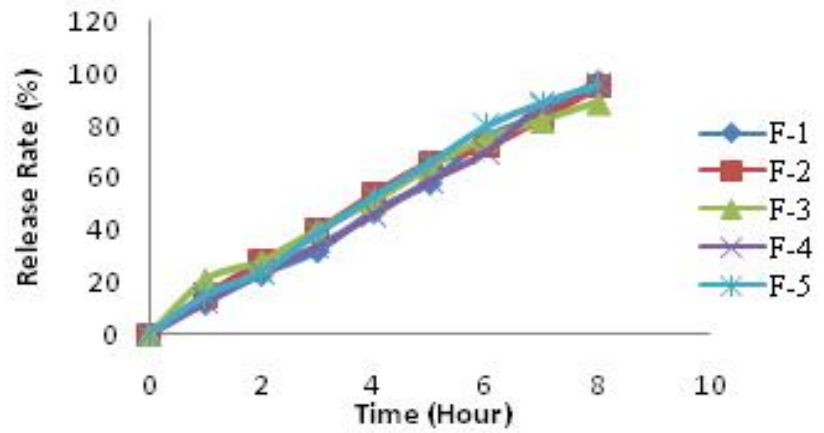

Fig. 3: Comparative Release Rate of different formulations containing natural polymers (Gum accacia based).

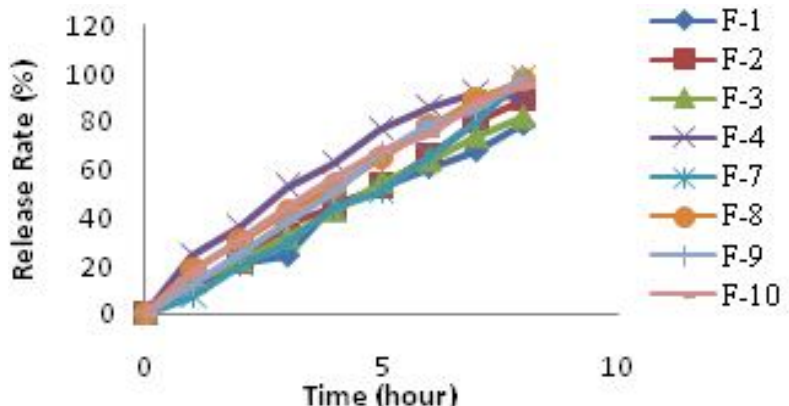

Fig. 4: Comparative Release Rate of different formulations containing synthetic polymers (HPMC $5 \& 15 \mathrm{cps}$ ).

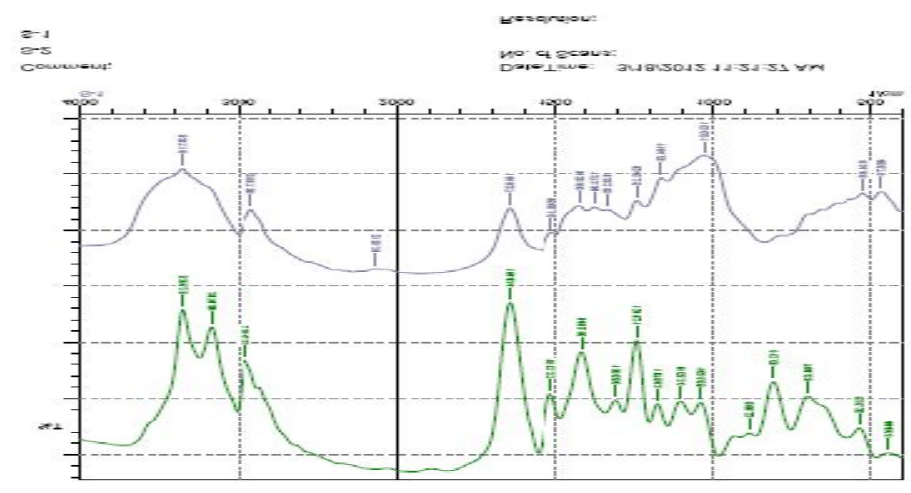

Fig. 5: FT-IR of atenolol and eudragit -ethyl cellulose synthetic polymer containing formulation. FT-IR Test showing no drug-polymer interaction.

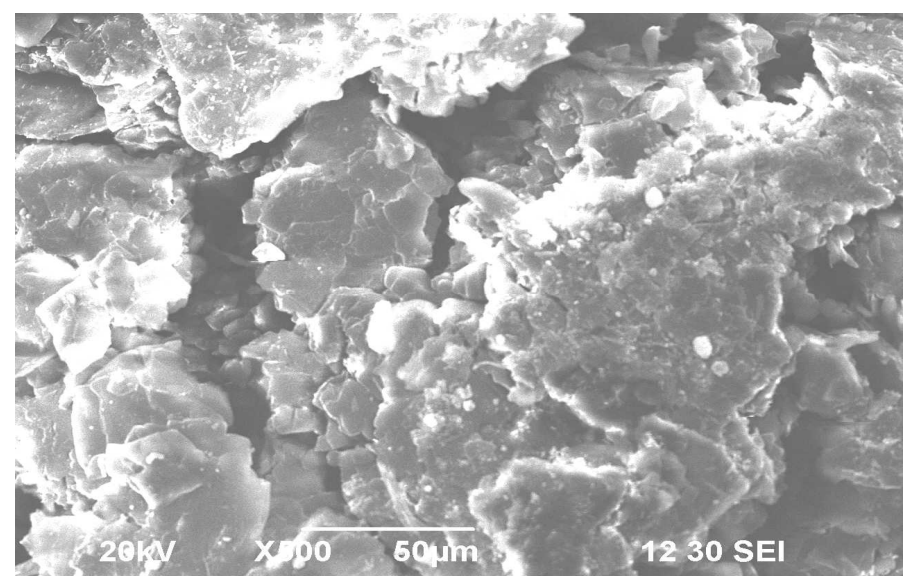

Fig. 6: SEM of f HPMC 5cps and Methyl Cellulose containing formulation .

If these two are compared then eudragit and ethyl cellulose containing formula [F-2] was better sustained release of atenolol SR containing synthetic polymers than starch and vee gum containing formula [S-3]. After the dissolution test of atenolol SR containing natural polymer starch [S-1], it was observed that dissolution rate was so fast which was exactly opposite to the principle of sustained release dosage form. So, starch at this concentration is not suitable for preparing SR .Dissolution profiles showed that better sustained release was observed from HPMC 5cps and Methyl Cellulose containing formulation (H-9) and Gum Accacia containing formulation (GA-1) of Atenolol matrix tablet. Again comparing these two formulations, it was observed that Gum Accacia containing formulation (GA-1) of Atenolol matrix tablet shows better sustained release effect than HPMC 5cps and Methyl Cellulose containing formulation (H-9).Again comparing with these two formulations, eudragit and ethyl cellulose containing formula [E-2] was better sustained release of atenolol SR containing synthetic polymers than Gum Accacia containing formulation (GA-1) of Atenolol matrix tablet.

\section{REFERENCES}

A. Strubel, J. Siepmann, A. Dashvesky, R. Bodmeier, pH independence release of a weakly basic drug from water-insoluble and soluble matrix tablets. J. Controlled Release, 2000; 67: 101-110. 
Agon P, Goethals P, Van Haver D, Kaufman JM. Permeability of the blood-brain barrier for atenolol studied by positron emission tomography. J. Pharm. Pharmacol, 1991; 43(8): 597-600.

Altaf AS, Friend DR. 2003. MASRx and COSRx SustainedRelease Technology in Rathbone MJ, Hadgraft J, Robert MS, Modified Release Drug Delivery Technology, Marcell Dekker Inc., New York.

Basak SC, Reddy BMJ, and Lucas Mani KP. Formulation and release behaviour of sustained release ambroxol hydrochloride HPMC matrix tablet. Ind J Pharm Sci, 2006; 68 (5): 594-598.

Bechgaar H., Baggeson S. Propoxyphene and norpropoxyphene: influence of type of controlled-release formulation on intra- and intersubject variations. J Pharm Sci, 1980; 69 (11) : 1327-1330.

J Cooper; G Gunn. 1986. Powder flow and compaction, In: Tutorial pharmacy, CBS Publisers, New Dehli. 211-233.

Lordi N.G. 1991. Sustained release dosage. In: Theory and practice of Industrial Pharmacy. 3rd ed, Varghese Publishing House. 430431.
ME Aulton; TI Wells. 1988. Pharmaceutics: The Science of Dosage Form Design. Churchill Livingstone, London, England.

MM Rahman; S Hasan; MA Alam; S Roy; MK Jha; MH Rahman. Formulation and evaluation of Ranolazine sustained release matrix tablets using Eudragit and HPMC. Int J Pharm Biomed Res, 2011; 2 (1), 7-12.

Suzuki, E. High-resolution scanning electron microscopy of immunogold-labelled cells by the use of thin plasma coating of osmium\& FT-IR. Journal of Microscopy, 2002; 208 (3): 153-157.

\section{How to cite this article:}

Adity Bhowmik, Rajia Sultana Nijhu, Tajnin Ahmed, Sharmin Sultana., Design and Development of Atenolol Matrix Tablet Employing Natural and Synthetic Polymers. J App Pharm Sci, 2013; 3 (09): 103-108. 